\title{
María Rosa Oliver: visible ausente. Una revisión del canon intelectual latinoamericano ${ }^{1}$
}

\section{Maria Rosa Oliver: The Visible Absent. Revisioning the Latin- American Intellectual Canon}

\author{
Vanessa Gómez Pereira \\ ONU mujeres, Bogotá, Colombia. \\ vangoper@gmail.com | https://orcid.org/0000-0002-6290-4473
}

Recibido: 10 de enero de 2019. Aprobado: 3 de junio de 2020

DOI: $10.25100 /$ lamanzanadeladiscordia.v15i1.8824

Artículo de investigación

¿Cómo citar este artículo? / How to quote this article?

Gómez, Vanessa. (2020). María Rosa Oliver: visible ausente. Una revisión del canon intelectual latinoamericano. La Manzana de la Discordia, 15(1), 171-208. doi:

10.25100/lamanzanadeladiscordia.v15i1.8824

\footnotetext{
${ }^{1}$ Este artículo se deriva de la tesis doctoral realizada por la autora. Quiero agradecer especialmente a Giovana Ortiz Suárez, a Mariana Betancur, a Juan Camilo Betancur y a Carlos Arturo López, cuyos comentarios y retroalimentación al primer borrador de este texto me permitieron estructurar mejor el argumento en estas páginas.
} 


\title{
Resumen
}

Este artículo examina el problema de la invisibilización del trabajo intelectual de la escritora argentina María Rosa Oliver (1898-1977) dentro del campo de los estudios literarios y culturales latinoamericanos. A partir de una investigación de archivo y del análisis de los discursos dominantes producidos en torno a sus escritos y figura, tanto entre sus contemporáneos como en la literatura actual, este texto rastrea las lógicas de heterodesignación vigentes en la concepción de lo intelectual, que han terminado desvalorizando un trabajo como el de Oliver. Apoyada en la crítica literaria feminista, planteo, no su inclusión en el canon, sino la necesidad de desmarcarse de los mecanismos vigentes de canonización para intentar nuevas lecturas sobre la literatura escrita por mujeres en el pasado.

Palabras clave: María Rosa Oliver, Canon, Intelectual, Obra, Literatura escrita por mujeres.

\begin{abstract}
This article examines the invisibilization of the intellectual work of the Argentine writer María Rosa Oliver (1898-1977) within the field of Latin American literary and cultural studies. Based on archival research and the analysis of the dominant discourses produced around his writings and figure, both among his contemporaries and in the current literature, this paper traces the logics of heterodesignation shaping the notion of the intellectual, and devaluing Oliver's work. Supported by Feminist literary criticism, I propose not her inclusion into the canon, but the urgency to dissociate us from the current mechanism of canonization to try new ways of viewing Women writing in the past.
\end{abstract}

Keywords: Maria Rosa Oliver, Canon, Intellectual, Work, Women Writing.

To evaluate noncanonical writing $[\ldots]$ you must first learn how to read it. To judge it on the basis of the established literary norms is by definition to pre-judge it, and reproduce the structure of exclusion that marginalized it in the first place. Canons are not just lists of books, but value machines that generate their own truth (Pratt, 1998, p. 87). 
"La responsabilidad del autor es inmensa, y difícil asumirla traduciéndola en obra", dice María Rosa Oliver en una charla pronunciada cuando se encontraba trabajando en el primer tomo de sus memorias ${ }^{2}$, que saldría publicado algunos años después bajo el título de Mundo, mi casa (Oliver, 1965). La dificultad de obra aparece desde el inicio de la reflexión de la autora en términos de un "largo debate" de consciencia y de vocación que, afirma, se le ha hecho apremiante bajo la interpelación de pares y periodistas, pues cuando la han entrevistado o requerido sus "datos biográficos", ha sido inevitable para ella tener que atender a la pregunta sobre cuántos libros ha publicado. "Bastante abochornada", aclara, se ha limitado a reportar apenas un par de títulos. Y continúa:

Al confesarme tan desprovista de obra editada [énfasis agregado] pasaban por mi mente las horas transcurridas tecleando en la máquina de escribir, los ensayos, los cuentos, las notas aparecidas en publicaciones diversas, y hasta en distintos idiomas, que no me di tiempo de recopilar, que reunidos formarían tres tomos y que nunca juntaré en volumen porque ignoro en qué archivos o anaqueles están amarilleando las páginas de los diarios y revistas en que aparecieron ${ }^{3}$.

Mundo, mi casa, donde Oliver narra su infancia privilegiada en un hogar de la alta burguesía porteña y el contagio de poliomielitis que le impidió volver a caminar, fue visto por sus contemporáneos como la notable expresión de una autora sin obra -con escasas publicaciones, pero con una trayectoria ejemplar-. La reseña que Victoria Ocampo (1965) dedicó en Sur a aquel tomo, se refiere a la narrativa biográfica de una mujer que logró demostrar "con su capacidad "la fecundidad de lo insuficiente"",4. El escritor argentino Pedro Orgambide elogió el libro de una "Trabajadora incansable de la cultura"5. Y el uruguayo Ángel Rama (1965) describió a Oliver como a una "animadora cultural" con una "asombrosa

\footnotetext{
${ }^{2}$ Charla/ensayo autobiográfico "El hoy y el recuerdo" [o "The Vocation of Being a Writer"], ca. 1962. Maria Rosa Oliver Papers, circa 1899-1997, Caja 1, Fólder 4. División de Manuscritos, Departamento de Libros raros y Colecciones especiales, Biblioteca central de la Universidad de Princeton [en adelante: MRO Papers, circa 1899-1997, Series, Caja no., Fólder no.].

${ }^{3}$ Charla/ensayo autobiográfico "El hoy y el recuerdo". MROP, Caja 1, Fólder 4.

${ }^{4}$ La noción empleada por Victoria Ocampo remite al concepto del conde de Keyserling, inspirado en Goethe, sobre los mecanismos compensatorios creados para reivindicar las deficiencias. En un testimonio sobre la argentinidad y su propia condición intelectual, Ocampo se refiere a la capacidad de escritores latinoamericanos, ella incluida, para apropiarse de referentes e idiomas y hacerlos propios: "Considero que nuestra apertura al mundo, este don nuestro de transformar en signo positivo un signo negativo, es una de las formas más felices y promisorias de aquella que Goethe llamaba la fecundidad de lo insuficiente" (Ocampo 1965, p.244). En el caso de Oliver, este signo negativo se refiere no a su condición de escritora latinoamericana, sino a la fuerza que la llevó a "solucionar el problema de una vida que podía frustrarse" (p. 244).

5 "Mundo, mi casa": en el viejo río de la memoria. 7 de junio, 1965. El Mundo (Buenos Aires). MRO Papers, circa 1899-1997, Series 7, Caja 9, Fólder 30.
} 
capacidad de recreación literaria", cuya "sillita de ruedas se hizo famosa en los congresos socialistas y en ella recorrió el mundo todo en varias direcciones" (p.29). Sin duda entre sus pares era difícil enmarcarla en una tarea específica del campo intelectual. El escritor Tomás Eloy Martínez (1969), por ejemplo, se refirió a ella como una "criatura inclasificable": elogiando ese primer tomo de sus memorias, aseguró que este "[e]s la mejor señal de que un testigo puede, a la vez, ser un creador de primer orden" (p.71). Lo cierto es que, para mediados de la década de 1960, María Rosa Oliver era una personalidad destacada de la intelectualidad latinoamericana ${ }^{6}$, aunque muy pronto llegó a ocupar un lugar invisibilizado.

Sus contemporáneos, colegas y allegados e ilustres intelectuales con quienes trabajó estrechamente en distintos frentes político-culturales, pese a no pocas veces reconocer su labor, continuamente reprodujeron un relato sobre sus escritos y sobre ella misma que terminó por ensombrecerla en la historia de la literatura argentina y latinoamericana. Y en el presente, en los estudios que tratan a Oliver y la historia de la literatura argentina sigue operando el lugar de una figura "menor" del campo intelectual de la primera mitad del siglo XX, a pesar de ser bien conocidos sus trabajos como traductora, asesora, escritora, editora y activista política. Son contados los análisis que se han ocupado de la obra de María Rosa Oliver hasta el momento.

El propósito primero de este texto es analizar el fenómeno de in/visibilización de la escritura y del trabajo intelectual de María Rosa Oliver con el fin de proponer a lo largo una reflexión sobre la prevalencia de las miradas canónicas y su intersección con sesgos históricos de género(s), clase, oficio, nacionalidad y dis/capacidad. La necesidad de plantear el problema de la invisibilización, siguiendo a Joan Scott (1992; 2001), parte del hecho de que "rescatar" es una tarea insuficiente si no nos lleva a interrogar las condiciones y los supuestos que han producido, en un contexto y momento determinados, esa diferencia; y el modo en que esta persiste. Es indispensable seguir cuestionando "por qué y cómo las mujeres se vuelven invisibles para la historia cuando, de hecho, fueron actores políticos y sociales en el pasado" (Scott, 1992, p. 47). El concepto feminista de heterodesignación ${ }^{7}$ es fundamental acá para

\footnotetext{
${ }^{6}$ Entre otras cosas, Oliver actuaba como consejera para Casa de las Américas y fue una de las primeras mujeres en componer el jurado del Premio Literario, en 1964, junto a la escritora dominicana Camila Henríquez Ureña, la poeta uruguaya Ida Vitale y la dramaturga chilena Isidora Aguirre. Antes de ellas, tres mujeres lo habían integrado: las entonces militantes políticas, colaboradoras de la institución, Mirta Aguirre en el año de 1960 y Natividad González Freire en 1962, además de la traductora argentina Aurora Bernal en 1963, mismo año en que participó con su esposo, Julio Cortázar. Cada vez se convocaban entre 15 y 20 personalidades para conformar el jurado del premio en las categorías de cuento, novela, teatro y poesía.

${ }^{7}$ Siguiendo las líneas de pensamiento de autoras como Virginia Woolf o Simone de Beauvoir, respecto del desconocimiento de LA mujer nombrada por la cultura patriarcal o de la propia asignación de lo natural y
} 
reconocer cómo los parámetros androcéntricos de obra y autor han definido los modos de valorar la literatura escrita por mujeres. En el caso de Oliver, como veremos, la negación histórica se expresa en forma de una cierta ficción heterodesignada que trivializa su papel en el mundo político y cultural de su tiempo. Difícilmente se le trata como escritora e intelectual. Toda esa obra dispersa y fragmentaria, mínimamente editada, que al final poco incomodaba a Oliver, nos habla de un hacer en el mundo intelectual que desafía formas normalizadas de ser mujer y escritora, y que ha de ser leída en sus propios términos para comprender las particulares y heterogéneas respuestas que han articulado las mujeres a través de la escritura en sus luchas tanto por la autodeterminación como por la transformación social.

La insuficiencia de la obra editada lo es también para Oliver: la responsabilidad inmensa del "escritor", nos dice, trasciende la (forma convencional de) obra. Las interpretaciones que rodean esa obra divergente se abordan acá a contraluz de una detallada investigación de archivo que ha permitido, por un lado, reconstruir y analizar más extensamente la práctica intelectual de María Rosa Oliver entre 1930 y 1965, y por el otro, problematizar los discursos dominantes que explican su sistemático ocultamiento. La invitación al enfocar primero estos últimos es, como se dijo, contribuir al debate sobre las lógicas que reproducen el sistema literario e intelectual como una maquinaria miope y excluyente de producción de valor. Con este fin sitúo brevemente, en primer lugar, la trayectoria de María Rosa Oliver en relación con la modernización de las actividades intelectuales y la ampliación de la participación de las mujeres en el campo cultural latinoamericano; para presentar en seguida una síntesis de la continua y heterogénea producción de Oliver en contraste con las lecturas que los contemporáneos produjeron en torno a su trabajo y figura. En particular, en el segundo apartado expongo la interconexión de prejuicios que terminaron afectando en su momento el reconocimiento de María Rosa Oliver como una escritora. En el tercero, hago un seguimiento a las lógicas del canon que se traslucen actualmente en la valoración histórica y literaria de una figura como María Rosa Oliver. Teniendo en cuenta lo anterior, planteo finalmente la necesidad de releer las tradiciones intelectuales y de las mujeres en América Latina.

\section{La vida de María Rosa Oliver}

femenino, críticas y filósofas feministas como Amelia Valcárcel o Celia Amorós han utilizado el término de heterodesignación para indicar las atribuciones de identidad de la que han sido objeto las mujeres, reconocidas en su posición funcional de sumisión. 
María Rosa Oliver nació en Buenos Aires, en el seno de una familia de origen patricio, el 10 de septiembre de 1898. A los diez años de edad contrajo poliomielitis y no volvió a caminar. Permaneció soltera. Su cuidadora, la gallega "Pepa", la acompañó a todos lados. Al igual que su entrañable amiga Victoria Ocampo, aprendió varios idiomas desde pequeña -en su caso, inglés, francés, alemán e italiano. Todos idiomas en los que hizo trabajo de traducción. Fue educada en casa por sus padres, con institutrices y maestros privados. El acceso de las mujeres a la educación era aún inusitado para ese momento, aunque desde finales del siglo XIX se contase con centros de primaria y Escuelas Normales femeninas en la Argentina ${ }^{8}$. En particular, para alguien como María Rosa Oliver, o su amiga Victoria Ocampo, la instrucción oficial en instituciones públicas no era un camino legítimo para su formación de clase y género. Pero el capital social y cultural que les permitió acumular su posición de clase se convirtió en una vía privilegiada de acceso al mundo intelectual de las décadas de 1920 y 1930 en Buenos Aires, aunque no en condición suficiente para zanjar las dificultades derivadas de su situación como mujeres escritoras.

Además de su participación en la creación de la revista Sur (1931), María Rosa Oliver fundó con Ocampo en 1936 la Unión Argentina de Mujeres (UAM) para promover el voto femenino; en 1939 ejerció como secretaria de la Comisión Argentina de Ayuda a los Intelectuales Españoles y en 1941, junto a Ocampo de nuevo, formó parte de la Junta de la Victoria - colectivo femenino creado para respaldar la causa aliada en la Argentina-. Entre 1942 y 1944, se desempeñó como asesora cultural en la Oficina Coordinadora de Asuntos Interamericanos de Washington. En 1949, se vinculó al Movimiento Internacional por la Paz, misión cultural más importante de la Unión Soviética al inicio de la Guerra Fría, donde militó junto a personalidades como Pablo Picasso, Pablo Neruda, Miguel Ángel Asturias, Simone de Beauvoir y Jean Paul Sartre. Colegas y allegados. Como lo fueron igualmente en su momento Borges, "Pepe” Bianco, Gabriela Mistral, las Ocampo, Alfonso Reyes y Waldo Frank. En 1957, obtuvo el Premio Lenin de la Paz. Perteneció a círculos antifascistas, feministas, comunistas, americanistas. Entre 1959 y 1977, escribió sus memorias: Mundo, mi casa (1965), La vida cotidiana (1969) y Mi fe es el hombre (1981), que abarcan desde los primeros años de infancia hasta su regreso a Buenos Aires en 1945, luego de concluir con su misión en Washington (Oliver, 1965; 1969; 1981). Viajera en América, Europa, Rusia, China, India y el

\footnotetext{
${ }^{8}$ La entrada irrestricta a centros educativos y universidades, así como el derecho al voto, serían dos de las principales luchas que darían las feministas argentinas durante las primeras décadas del siglo XX. Ver, por ejemplo, Las argentinas de ayer y hoy de Lily Sosa de Newton (1967), uno de los primeros estudios comprehensivos sobre la historia y situación de las mujeres en la Argentina. Sobre su participación en la educación y el magisterio, ver también Barrancos (2008) y Palermo (2006).
} 
entonces Ceylán. Dejó huella de un extenso epistolario con personalidades de diferentes latitudes y, asimismo, una amplia colección de textos publicados, también de borradores, manuscritos, traducciones, diarios y memorias de viaje, conferencias, informes y discursos ${ }^{9}$.

Una idea como la de "Trabajadora de la cultura" apela ciertamente a una prolífica actividad en el campo intelectual argentino y latinoamericano, si bien indica una posición difícil de aprehender: una identidad pública a la vez prominente y ambigua. Sin duda, estas imágenes permiten concebir una heterogeneidad productiva tan distintiva como propia de las condiciones en las que se fue constituyendo el trabajo intelectual de su generación. Por un lado, se halla la consolidación de la idea moderna de intelectual como un ejemplo de convicción, disidencia y compromiso social (Altamirano, 2013; Baert, 2015; Bourdieu, 2002; Dosse, 2007), así como la popularización del término luego de la Segunda Guerra Mundial, sobre todo en medios culturales de izquierda. Para finales de la década de 1920, la categoría de intelectual era ya de uso corriente en América Latina (Altamirano, 2008). Por el otro lado, estas reflejan de alguna manera el acelerado proceso de modernización que se experimentó en América Latina desde el último tercio del siglo XIX, y que permitió una creciente participación de mujeres letradas en diferentes áreas del mundo cultural durante la primera mitad del XX (Masiello, 1997; Salomone, Luongo, Cisterna, Doll y Queirolo, 2004; Salomone, Amaro y Pérez, 2010; Sarlo, 2003). Como explica el propio Ángel Rama, la diversificación, extensión y democratización de los espacios de producción cultural implicó la proliferación de nuevas funciones asociadas con la escritura: "el brusco avance de la prensa absorbió prácticamente a todos los escritores existentes” (Rama, 1985, p.35).

Lo anterior supuso tanto la ampliación de espacios de enunciación para voces antes marginadas, como la delimitación de nuevos oficios y jerarquías profesionales -periodismo, docencia, traducción, edición, entre otros-. En este contexto, las sistemáticas aportaciones y vinculación de las mujeres a revistas o publicaciones seriadas, ponen en evidencia, siguiendo a Bergmann et al. (1992): "the reality of women's writing but also women's editing, printing, selling advertisements and subscriptions, planning, fighting censorship, and spending money - their own and other people's (Victoria Ocampo and Clorinda Matto de Turner both founded publishing houses)" (p.178). La actividad de estas, en pocas palabras, no solo se hizo

\footnotetext{
${ }^{9}$ Hoy, en su mayoría, alojados en el repositorio documental de María Rosa Oliver en la Universidad de Princeton, donde llevé a cabo el trabajo de investigación para mi tesis doctoral, enfocada en la reconstrucción del trabajo intelectual de María Rosa Oliver entre 1930 y 1965, desde su vinculación al proyecto de la revista Sur hasta la publicación del primer tomo de sus memorias.
} 
presente de distintas maneras durante este periodo, sino que contribuyó a la modernización y configuración de las nuevas formas de producción cultural.

En su investigación sobre la integración de las escritoras al mundo literario de las décadas de 1920 y 1930, particularmente en el periodo de auge de las vanguardias latinoamericanas, Vicky Unruh (2006) analiza el performance literario a través del cual mujeres como Victoria Ocampo, Alfonsina Storni, Nora Lange, Antonieta Rivas Mercado, Magda Portal, y algunas otras, buscaron establecer su propio hogar intelectual. Unruh se refiere a la posición ambivalente que estas asumieron. En general, hay un reconocimiento de la "rigidez" de este contexto y de la dificultad para consolidar una suerte de espacio de producción en el centro. Pero entre la crítica y la adopción de las representaciones sobre la mujer moderna y sobre los efectos de la modernización en sus vidas y potencialidades, estas mujeres lograron abrirse camino y hacerse un lugar en el campo cultural del momento.

El trabajo intelectual de María Rosa Oliver se articula en estas condiciones. Junto a mujeres como Victoria Ocampo, Gabriela Mistral, Silvina Ocampo, pero también a escritores como Jorge Luis Borges, Eduardo Mallea o Alfonso Reyes, Oliver cumplió tareas diversas como escritora, gestora cultural, traductora y editora. Sin embargo, a diferencia de estos, ella terminó resistiéndose a procesos de consolidación pública que permitiesen fijar su identidad en el campo intelectual dentro de uno de los oficios existentes. En especial, como veremos, el de ser escritora. A pesar de que, como Ocampo y Mistral - dos de sus contemporáneas y amigas cercanas-, hoy nombres luminosos de los estudios culturales latinoamericanos, María Rosa trazara un marco de acción transnacional y llegara a ocupar un lugar central en diferentes círculos intelectuales de la región, su trabajo es hoy prácticamente desconocido. Pero no por una "falta" de obra o por su irrelevancia, sino por el modo y el tipo de trabajo que llevó a cabo. Su proyecto intelectual, e incluso su obra, su idea misma de la actividad intelectual, no respondían al statu quo del gran escritor.

\section{2. "Becoming a writer"}

Cuando supo de la publicación del primer volumen de las memorias de María Rosa Oliver, el escritor estadounidense Waldo Frank le decía en una carta a su amiga:

You are becoming a writer. Your letter shows it, (creative women develop, usually, later than men) [énfasis agregado]. Your instinct to 
travel less, attend congresses less, and remain more at home to let the spring waters rise to the pool, is, I feel sure, correct $^{10}$.

Hay una dimensión del trabajo del "escritor" que excede a la producción escrita y que, en ese sentido, no puede reducirse a una visión normalizada de lo que supone "hacer" obra. Tomar como punto de mira a figuras canónicas impide el reconocimiento de otras facetas del trabajo intelectual llevado a cabo a través de la escritura. Por ello, examinar un caso como el de María Rosa Oliver permite concebir el negativo de aspectos no solo de la concepción de obra y de los géneros literarios, sino también de la condición misma de ser mujer y discapacitada en relación con el oficio de la escritura. El comentario de Frank, en particular, revela una primera exigencia del "escritor": la presunta oposición con la "acción" -el hacer en viajes, congresos, colectivos- y la sistematicidad que dará unidad a una obra. Más importante aún, con su carta, Frank manifiesta no una consideración sobre las condiciones sociales que podrían explicar tal desarrollo tardío, sino un prejuicio sobre la creatividad y autorías femeninas que en efecto desconoce, como se verá, el trabajo realizado.

Antes de la edición de sus memorias, en 1955, María Rosa Oliver había publicado en co-autoría Lo que sabemos hablamos...Testimonio de la China de hoy (1955), un libro de testimonio sobre su viaje a la República Popular China -y el de parte de la delegación argentina que asistió al Congreso de Partidarios por la Paz, celebrado en Viena en diciembre de 1952-. En 1945, había sido editada una compilación de sus charlas radiales sobre la sociedad y la cultura norteamericanas, pronunciadas ese mismo año, como parte de las actividades apoyadas por la Comisión Argentina de Fomento Interamericano. En 1939, María Rosa Oliver publicó su Geografía infantil de la Argentina. Ningún otro libro. Entre uno y otro, Oliver produjo una amplia variedad de textos editados en periódicos, revistas políticoculturales y literarias de Argentina, América Latina y Europa -Sur, Correo literario, Cuadernos Americanos, The Inter-American Quarterly, Casa de las Américas, Horizons, son algunos ejemplos. "La distinguida intelectual y escritora argentina María Rosa Oliver", anunciaba en 1944 el periódico El Tiempo de Bogotá, "traza un paralelo entre las letras del norte y las letras del sur" en una charla sobre literatura norteamericana, dictada en la Universidad Nacional de Colombia. Por esa época, la prensa en Ecuador, Perú, Brasil, Argentina registraba a su paso las conferencias de "la escritora argentina", destacada

\footnotetext{
${ }^{10}$ Carta de Waldo Frank a María Rosa Oliver, 13 de octubre, 1965. MROP, Caja 3, Fólder 50.
} 
integrante del Consejo Editorial de Sur, redactora allí y en La Nación de Buenos Aires ${ }^{11}$. En 1937, fue publicada su primera traducción al español: la novela City Block (1922) de Waldo Frank.

María Rosa Oliver escribió sobre la literatura norteamericana de la "generación perdida” en la década del treinta del siglo XX, sobre la política cultural estadounidense durante los años de Buena Vecindad, sobre Brasil y distintos paisajes de América Latina hacia el final de la Segunda Guerra Mundial. En ese periodo escribió asimismo sobre las biografías, el crecimiento de la ciudad, el género epistolar, los derechos civiles de las mujeres, Cantinflas, el teatro y el cinematográfico hispanoamericano. Luego sobre la política anticomunista del Departamento de Estado y el imperialismo agresivo tras la muerte de Roosevelt. A lo largo de la década de1950, escribió sobre la amenaza atómica, la guerra en Corea, las dictaduras en América Latina, los congresos pacifistas en diferentes partes del mundo, el conflicto árabe-israelí, sus viajes a China, a Rusia y al entonces Ceylán. En los años 1960, mientras trabajaba en sus memorias, escribió sobre la literatura de testimonio, sobre su paso por la Habana y su encuentro con el Che Guevara. En su mayoría, desarrollados estos a través de ensayos breves, análisis políticos, crónicas, entrevistas, reseñas, textos de crítica literaria y de arte, semblanzas, impresiones de viaje e incluso algunos cuentos.

Como se puede ver, el trabajo de escritura en la trayectoria de María Rosa Oliver es una constante. Pero sus publicaciones en forma de libro, en primer lugar, son escasas. Sumado a ello, por el tipo de textos y por varios de los medios en los cuales publicó, gran parte de esa producción difícilmente habría podido ocupar una zona central en el registro literario de su tiempo. El vasto de esta producción prevalece in-visibilizada. Siguiendo a Joana Russ (2018), entre los múltiples mecanismos que han funcionado históricamente para anular la autoría femenina, el desconocimiento arriba señalado podría considerarse como una forma de "negación por medio de la falsa categorización": subestimar una obra o autora al renombrarla para cambiar su significado. Y esto en dos direcciones: al "trasladar las cosas que existen" a la categoría de las que no existen -no reconocer trabajo de escritura previo al de

\footnotetext{
11 "María Rosa Oliver, Ilustre Escritora Argentina, Llegó a Bogotá en Viaje a su País" (2 de septiembre, 1944) y "La conferencia de María Rosa" (7 de septiembre, 1944), El Tiempo (Bogotá, Colombia); "Sobre sus observaciones en los países americanos habló por radio la escritora María Rosa Oliver (Se suspendió la ignorancia mutua entre nuestros países)" (12 de septiembre, 1944) y "La escritora María Rosa Oliver fue recibida por la Unión Nacional de Periodistas" (septiembre, 1944), periódicos no especificados (Quito, Ecuador); "En Insula ofreció ayer una charla la escritora Srta. María Rosa Oliver" (15 de septiembre, 1944), La Crónica (Lima, Perú); "El Brasil de María Rosa Oliver" (1944) El Correo Literario, año II, no. 9 (Buenos Aires, Argentina). MROP, Series 7, Caja 3, fólder 47.
} 
sus memorias- y "la de trasladar el objeto de arte X de la categoría de 'arte serio' a la de 'no serio"” (Russ, 2018, p.110).

Críticas e historiadoras culturales feministas han mostrado cómo buena parte de la escritura de mujeres ha tenido lugar a través de cartas y diarios -textos que no siguen normas literarias y no son pensados para su publicación-, pero también a través de prosas autobiográficas, testimoniales, crónicas, ensayística de género -en términos de Pratt (1998)${ }^{12}$, que suelen aparecer como producciones secundarias, irrelevantes o menores ${ }^{13}$. Pero como bien lo ha demostrado Josefina Ludmer en su ya clásico ensayo "Las tretas del débil", las mujeres, en cuanto subalternas, han usado los géneros y la sintaxis permitida para subvertir las posibilidades de enunciación frente a la designación dominante. Lo que el canon pierde de vista, en este sentido, es el hecho de que:

La treta (otra típica táctica del débil) consiste en que, desde el lugar asignado y aceptado, se cambia no sólo el sentido de ese lugar sino el sentido mismo de lo que se instaura en él [...] Ante la pregunta de por qué no ha habido mujeres filósofas puede responderse entonces que no han hecho filosofía desde el espacio delimitado por la filosofía clásica sino desde otras zonas, y si se lee o se escucha su discurso como discurso filosófico, puede operarse una transformación de la reflexión. Lo mismo ocurre con la práctica científica y política (Ludmer 1985, pp. 51-52).

Aunque en su mayoría estos géneros literarios fuesen también practicados por escritores varones reconocidos -sobre todo con el auge de formatos aparejados al proceso de modernización cultural-, su estatus de "arte no serio" persiste en los recuentos literarios. Si en el caso de escritores como el mexicano Alfonso Reyes o el dominicano Pedro Henríquez Ureña, las espístolas podrían tenerse a la vez como evidencia de una consecuente calidad literaria, en el caso de una mujer como María Rosa Oliver, estas, solo ante el anuncio de una obra en gestación, parecen revelar verdadera calidad literaria. "Your letter shows it", dice Frank. Pero esa carta es una de las últimas entre decenas de las que intercambiaron durante

\footnotetext{
12 "El ensayo de género" es identificado por Marie Louise Pratt (1998) como un proyecto ensayístico practicado por mujeres, desde comienzos del siglo XIX, como un modo de contestación al monólogo masculino encarnado en el género dominante del ensayo de identidad latinoamericana. Este corresponde, según Pratt, a una colección de textos escritos por mujeres latinoamericanas y enfocados en el estatus social de las mujeres.

${ }^{13}$ Ver, por ejemplo, trabajos y compendios como los de Ecker (1986), Blazquez Graf y Castañeda Salgado (2016), Russ (2018), Weigel (1986), y en el caso latinoamericano, Salomone et al. (2004; 2010), Pura Fernández (2015) y Alzate y Doll (2014).
} 
más de tres décadas de amistad. Y el juicio del escritor estadounidense, como se verá en seguida, es ciertamente representativo de las concepciones que rodearon un trabajo literario e intelectual como el de Oliver. Ella misma pone en evidencia la tensión entre el (auto)reconocimiento y el desconocimiento de su escritura al indicar, con sutil ironía, la vergüenza que le produce tener tan escasos títulos editados, frente a las largas y constantes horas transcurridas con su máquina de escribir y las piezas o páginas dispersas, no por ello menos relevantes, donde incluye "las notas combativas o esclarecedoras sobre problemas del momento", "la redacción de manifiestos y arengas" y "la composición de discursos para asambleas o congresos" $" 14$.

Pocos años después de su muerte, el escritor argentino Pedro Orgambide aseguraba: "María Rosa Oliver escribió centenares de artículos, notas críticas, ensayos y se acercó a la ficción a través del cuento. Fue autora de una Geografía infantil de la Argentina. Pero su aporte singular a nuestra literatura, queda en sus libros de memorias" (Orgambide, 1988). Estas memorias son una especie de obra tardía, reunida en tres tomos, que le ha valido la inclusión en algunas enciclopedias de literatura argentina y latinoamericana. Una de las primeras, la explicaba así: "No se ocupó de reunir todos sus trabajos en volumen porque por un prodigio de vitalidad interior y de espíritu social se ha realizado sobre todo a través de la acción" (Orgambide y Yahni, 1970, p. 481). En las reseñas sobre la primera entrega de su autobiografía, Oliver era presentada a veces como una escritora constante, "con una vasta labor periodística", capaz de entregar un testimonio comparable a "Infancia, adolescencia y juventud de Tolstoi” ${ }^{\prime 15}$, pero con una producción asimismo fraccionada e inacabada ${ }^{16}$.

En contraste con la atención que recibieron los dos primeros tomos de su autobiografía, editados ambos durante la década de 1970, el tercero de la serie, aparecido unos años después de su muerte, pasó prácticamente inadvertido (Fernández, 2008). La vida cotidiana, por ejemplo, llegó a integrar la lista de los más vendidos en 1969. El libro de 1981, en cambio, era el de una mujer cuyo nombre se había comenzado a desvanecer de los frentes intelectuales. "Su autora había perdido protagonismo en el mundo cultural porteño", asegura Fernández Bravo (2008, p. 47). En parte, esto podría entenderse en términos de lo que

\footnotetext{
${ }^{14}$ Charla/ensayo autobiográfico "El hoy y el recuerdo" [o "The Vocation of Being a Writer"], ca. 1962. Maria Rosa Oliver Papers, circa 1899-1997, Caja 1, Fólder 4.

15 "Mundo, mi casa de María Rosa Oliver" (por Carlos Ruíz Daudet). Octubre de 1965, Renovación no. 80. $M R O P$, Caja 9, Fólder 30.

16 "A la luz de la infancia". 15 de junio, 1965. Primera Plana (Buenos Aires); "Memorias, visiones y nostalgia de una sagaz intelectual". Octubre, 1965, Panorama; "Las mujeres jóvenes se ríen del feminismo... pero no saben que hace dos generaciones sus abuelas lucharon por ellas" dice María Rosa Oliver. 29 de agosto, 1965. Revista Vosotras no. 1549 (Buenos Aires). MROP, Caja 9, Fólder 30. También Rama (1965).
} 
Bourdieu (2002) denominó “envejecimiento social”, un proceso de caducidad de posición en el campo cultural. Sin otra obra evidente que sus memorias, no del todo concebidas como declaración de una escritora ${ }^{17}$, Oliver era más bien representante de un orden que, con el tiempo, ciertos intelectuales de las "nuevas izquierdas" argentinas llegarían a reducir a un comunismo chic o bienpensante.

Apoyado en las explicaciones que ofrece Oliver en el tercer tomo de sus memorias, sobre el trabajo que realiza como asesora del gobierno Roosevelt, David Viñas escribe con evidente acidez: "lo que ocurre, desdichadamente, es que la Oliver incurre con frecuencia en los gestos bienpensantes [...] olvidándose de que los Estados Unidos son el mercado mayor donde todo se convierte explícitamente (y sin mojigaterías) en mercancía" (Viñas 2008, pp. 309-310). El crítico Juan José Sebreli (2005), por su parte, propone una caracterización en buena medida acorde con esta perspectiva: en su propia autobiografía, recuerda que él y otros de sus compañeros, siendo jóvenes y "sofisticados intelectuales marxistas", consideraban a María Rosa "demasiado ingenua y superficial” (p. 229). En cuanto modelo de la "era estaliniana", presenta a Oliver como la "aristócrata convertida al comunismo, 'la duquesa roja', 'la dama del Kremlin'”, y reduce su trabajo y trayectoria al de una "idealista que ignoraba los hilos secretos propios de la política totalitaria" (Sebreli, 2011, p. 92). Pero ninguno de los intelectuales de su tiempo, como bien ha demostrado el trabajo de Iber (2013; 2015), se escapó a la lógica bipolar o al apoyo, tácito o explícito, a consciencia de los hilos ocultos o no, de órdenes represivos.

A veces sencillamente considerada como una importante mujer del mundo cultural argentino o, según se aclararía en una de las reseñas de Mundo, mi casa, como "una mujer que llegó a crearse una vigorosa personalidad en nuestro medio" ${ }^{\prime 18}$, la identificación intelectual de Oliver se complejiza. Pese a ser muchas veces reconocida como una intelectual de orientación comunista o integrante de las izquierdas argentinas, entregada además a diversas causas sociales, su imagen como tal está simultáneamente cargada de trivializaciones -por ser mujer o por ser de la alta burguesía-, o bien convertida en virtuoso y público modelo de cuidado y

\footnotetext{
${ }^{17}$ Por ejemplo, en su evaluación de Mundo, mi casa, Ángel Rama (1965) elogiaba cómo la veracidad del libro era en parte delatada por "la asombrosa capacidad de recreación literaria" (p. 29) de una mujer que no es "narradora", es decir, que no se ha destacado como una autora de narrativa.

18 "Mundo, mi casa. En el viejo río de la memoria". 27 de junio, 1965, periódico El Mundo. MROP, Caja 9, Fólder 30.
} 
superación personal. Sin haber sido una verdadera estudiosa del materialismo dialéctico ${ }^{19}$, se afirma por ejemplo en la nota de la revista Confirmado:

María Rosa Oliver no es una representante común de la izquierda intelectual argentina [...] Algunos, por no conocerla, la suponen una snob de la subversión; otros creen que en su vida no hizo más que aportar dinero a entidades colaterales del comunismo y firmar declaraciones 'democráticas'. Ignoran su fundamental, incontrolable bondad $^{20}$

Más adelante, luego de exaltar el valor de haber convertido la lucha contra la "quietud física" en compromiso social, la nota acredita: "María Rosa Oliver es quizá, sólo altruismo; y sus simpatías por determinados sectores políticos parecen movidas más por la generosidad que por la ideología"21.

La anterior referencia remite tanto a las ideas comunes de descalificación (entre quienes no la conocen de verdad), como a una fuente de reivindicación que, por lo demás, es coherente con las tradicionales representaciones que hacen de la presencia y actividad de las mujeres en el espacio público una muestra de virtudes o inclinaciones propiamente femeninas (abnegación, servicio al otro, instinto maternal) ${ }^{22}$ aguzadas por efecto de la supuesta benevolencia asociada con la condición de discapacidad de Oliver. Este uso un tanto mistificado de la enfermedad -en este caso de una enfermedad que ha dejado huella perceptible y permanente en el cuerpo-, como ya lo ha señalado Susan Sontag (1991) en relación con los mitos sobre el cáncer y la tuberculosis, arrastra fantasías de distinto orden que, siguiendo un pensamiento metafórico, intervienen la posibilidad misma de captar a la persona, sus afectos, temperamento, y en este caso, al parecer, también su capacidad literaria

\footnotetext{
${ }^{19}$ La misma Oliver es reticente a este respecto. Según se cuenta en la nota, la autora de Mundo, mi casa confiesa que no se dedicó en verdad a comprender el "materialismo dialéctico" a lo largo de su vida. Teniendo en cuenta que algunos de los círculos de socialización político-intelectual donde estuvo involucrada Oliver, incluida su corta pertenencia al PC, entre 1934 y 1936, le permitieron acercarse, discutir e integrar nociones del marxismo a su concepción del mundo por comprender y defender, la reserva manifestada en este espacio remite más bien al hecho de no haber dedicado obra de estudio alguno a ese tema, de no ser una estudiosa o filósofa del marxismo en ese sentido.

20 "María Rosa Oliver: el amor militante". 10 de marzo, 1966, revista Confirmado, p. 64. MROP, Caja 9, Fólder 30.

21 "María Rosa Oliver: el amor militante". 10 de marzo, 1966, revista Confirmado, p. 64. MROP, Caja 9, Fólder 30.

${ }^{22}$ El estudio de Fiol-Matta (2002) sobre la icónica construcción de Gabriela Mistral como la "Madre de América", o la profesora-madre de la nación, es ejemplar en este sentido, pues pone en evidencia cómo un cuerpo o imagen que bien puede tenerse por queer, ambivalente en su performatividad pública, participa de los discursos normativos - y cómo la afirmación o desviación de este modelo afecta igualmente su consagración y reconocimiento históricos-.
} 
e intelectual. Las responsabilidades del intelectual o "escritor" comprometido, tan caras para su generación, quedan intersectadas acá por la preeminencia de sesgos relativos al ser mujer y discapacitada -y la correspondiente trama de "fantasías" vigentes- ${ }^{23}$.

"No conocerla", en particular, sugiere el vacío de un acervo literario o filosófico que dé cuenta de esa labor pública. Incluso, en lecturas favorables a la labor pública de Oliver o en medios de izquierda donde ella escribió (como el diario Propósitos de Buenos Aires), las referencias a la ausencia de una obra distinta a su autobiografía suelen aparecer como un claro vacío. Comentarios como los de Rama, quien resalta su capacidad narrativa pese a no ser escritora, es también muestra de ello. Al salir la Vida Cotidiana, por ejemplo, se la presentaba de este modo en la revista Panorama:

Más que una escritora es una mujer que escribe y aunque mantiene celosamente ocultas muchas pasiones, que sólo a ella le pertenecen, sabe tomarse en broma y no renuncia a describir debilidades ajenas. Cuando el tema exige surge una poderosa página de altísima calidad literaria ${ }^{24}$.

Todavía unos años atrás, cuando Oliver fue galardonada con el Premio Lenin de la Paz en 1957, y antes de la publicación del primer tomo de sus memorias, Jorge Luis Borges comentaba a su amigo Bioy Casares:

Todos saben que es una farsa ¿Qué hizo María Rosa en favor de la paz? ¿Dónde están sus elocuentes publicaciones? Es como si le dieran el premio de la paz al ratón Mickey. Estela me contó que en Rusia los paisanos besaban las manos a María Rosa porque creían que había

\footnotetext{
${ }^{23}$ Las conceptualizaciones críticas frente a las distintas formas de discapacidad, sus determinaciones y los estigmas e imaginarios ligados a esta, se desarrollan en los Estados Unidos durante la década de 1970 como resultado del movimiento social que reivindica su reconocimiento en cuanto expresión de las desigualdades producidas por insuficiencias del medio y por los prejuicios de normalidad. Simultáneamente en diálogo y tensión con otras corrientes críticas culturales -los múltiples movimientos de liberación, las luchas por los derechos civiles, los grupos LGBT, los feminismos-, el activismo por los derechos de las personas discapacitadas, impulsa igualmente la posterior consolidación del área interdisciplinar de los Disability Studies (Frank, 2000). Este es, todavía hoy, un campo de estudios marginal en América Latina. Por ahora, llamo la atención sobre este antecedente para indicar justamente que, al momento de articulación de dichas nociones sobre la enfermedad-discapacidad y la obra de Oliver, no cabe atender sino a una matriz de sentido común que revela, digamos, otro tipo de representaciones atadas al género y a las posibles cualidades de una escritora. Sentido común que "irrumpe" y se hace palpable en el campo intelectual y literario, tal como lo entiende Bourdieu; es decir, que afecta de alguna manera el sistema, aunque no corresponda con las formalidades de sus apreciaciones estéticas.

24 "Memoria de una pasión argentina". 24 de noviembre, 1969, revista Panorama. MROP, Caja 9, Fólder 33.
} 
quedado tullida en sus luchas contra el capitalismo (Borges junio 6 de 1958, citado en Bioy, 2006, pp. 447-448).

E insistía en seguida: “¿Cuál es la obra de María Rosa? Ese libro disparatado que escribió con Frontini Lo que sabemos hablamos...". El para entonces ya reputado escritor, representante de los denominados sectores liberales y democráticos, primero allegado de Oliver en la empresa Sur, luego su antagonista político, no demerita en un primer momento el valor del premio por ser símbolo de la "paz comunista", como la calificaban quienes cuestionaban al Movimiento Internacional por la Paz, sino porque la galardonada no tenía si quiera una obra que fundamentara algún trabajo intelectual ${ }^{25}$.

Más allá del Affaire ideológico que hay detrás ${ }^{26}$, cabe destacar la imagen general que presenta: la banalización e infantilización de una figura femenina y de su papel en el mundo intelectual, a falta de una "obra" que la redima. La caricaturización se profundiza ante la imagen de una mujer en silla de ruedas. Sin “elocuentes publicaciones” ¿qué puede ser? ¿una ficha? ¿un símbolo? ¿una curiosidad? También la parodia de señalar a una "tullida" (de la alta burguesía porteña) que pareciera haber perdido la habilidad de caminar en su militancia anticapitalista. Además de la intersección de lecturas sobre esa in/visibilidad -mujer, discapacitada, burguesa, seudo escritora-, queda claro en boca del escritor qué es lo que se supone puede/debe hacer, en sentido amplio, un intelectual. Ahora, si tenemos en cuenta las dos circunstancias adicionales de que el propio Borges no adhiere a la idea militante del "escritor comprometido" y de que él encarna entonces la autoridad del canon literario, vemos la anulación que se produce por efecto de desplazar la relevancia del trabajo de Oliver por la paz al del campo (de oposiciones) literario. Al descalificarla, lo hace como presunta escritora e impone criterios ajenos al de un tipo de reconocimiento para una obra de lucha. Frente a esta mirada, cabe hacerse la pregunta más fundamental de qué elocuencia pide entonces el canon: la facultad primero de decir algo, unicidad, no cosas dispersas, y la capacidad en seguida de hacerlo bien. En esta esfera, infantilizarla implica hacerla irrelevante política, teórica y estéticamente, atarla a la ingenuidad y a la minoría de edad.

\footnotetext{
25 “Mundo, mi casa de María Rosa Oliver” (por Carlos Ruíz Daudet). Octubre, 1965, Renovación no. 80. MROP, Caja 9, Fólder 30.

${ }^{26}$ Oliver fue galardona como partidaria del movimiento cultural internacional entonces respaldado por la Unión Soviética, y Borges, su colega en el comité de redacción de Sur, hizo parte en cambio del grupo de intelectuales asociados al Congreso por la Libertad de la Cultura, frente cultural promovido por el bloque occidental. Como nota al pie, cabe destacar que en 1966, en un reportaje del New York Times, se destapó que el CLC era financiado directamente (en secreto) por la CIA.
} 


\section{El canon masculino}

En la breve entrada sobre María Rosa Oliver de la Encyclopedia of Twentieth-Century Latin American and Caribbean Literature, Daniel Balderston (2004) afirma, luego de señalar que esta fue activista y víctima de la polio: “Oliver's memoirs are her most significant work" (p. 395). El grueso de lo escrito por María Rosa Oliver, como indiqué arriba, integra en realidad una variopinta colección de formatos que podrían quedar comprendidos dentro de lo que se conoce como "géneros menores", en su mayoría dispersos, inéditos o invisibles, difícilmente comprendidos como la obra de una "gran escritora". Los "géneros menores" tienden a agrupar diarios, cartas, letras de canciones, ensayos cortos, poesía sentimental, crónicas, comentarios, reseñas, apuntes y, en general, toda una serie de expresiones textuales, también de sujetos, que se "desvían", por fuerza de prácticas excluyentes o de gestos contestatarios, del canon literario y de pensamiento (Salomone, Amaro y Pérez, 2010); es decir, de esa selección de textos que se suponen representativos de los más "altos valores" estéticos e intelectuales en determinados contextos y momentos históricos, y cuya centralidad coincide con lo realizado por grupos, instituciones y tradiciones críticas dominantes. Entre los géneros menores indicados hay en común un registro personal de la escritura que se alza desafiante ante cualquier pretensión de universalidad. Lo sistemas canónicos, en palabras de Mary Louise Pratt (1998) son:

self-confirming structures, reproducing themselves through practices of reading, in the most basic aspects of literary experience, such as horizons of expectations, genre, subject of matter, language or point of view. Readers trained in/on canonical texts, it follows, are by definition unequipped to evaluate texts by subordinated or excluded groups. They will invariably misread such material, dislike it, dismiss it as illegible or (more likely) trivial in content and form (p. 87).

Si examinamos un juicio como el de Borges, motivado también por recelos ideológicos y por desencuentros personales, vemos pese a ello cómo delata la prevalencia del hombre de letras en la concepción de lo intelectual. Hasta entrada la década de 1960, con frecuencia se utilizan de modo indistinto las categorías de "intelectual" y de "escritor" en América Latina. O más bien, a todo escritor reconocido le cabía por extensión el título de 
intelectual ${ }^{27}$. Si bien la nominación es oscilante, con frecuencia, presupone un tipo de productividad que encarne formas dominantes de expresión: filosofía, narrativa, poesía (no sentimental o de amor), ensayo. En particular, este último género, retomando a Pratt (1998), ha cumplido un papel fundamental en el canon del pensamiento latinoamericano a través de lo que ella denomina criollo identity essay o "ensayo de identidad": una serie de textos producidos desde inicios del siglo XIX por hombres usualmente pertenecientes a las élites euroamericanas y cuyo objeto central de indagación ha sido la naturaleza de la identidad latinoamericana, en relación, sobre todo, con Europa y Estados Unidos. Desde lo clásicos ensayos de Martí y de Rodó, hasta El Calibán de Fernández Retamar, se ha hecho claro que el portador de este linaje, "[i]s the figure of the pensador, the thinker, propietor and producer of el pensamiento, from which women were by their nature excluded" (Pratt 1998, p. 89). Es bien conocida la relevancia que tuvo esta figura intelectual en la lectura del pasado literario, y su asociación con el ejercicio de los poderes centrales, desde que Ángel Rama publicara su ya clásico estudio "La ciudad letrada". Instituido en la autoridad de la letra desde época colonial, el orden letrado ha instituido siempre prácticas tendientes a su reproducción como núcleo del ordenamiento social (Rama, 1998).

Ahora bien, el perfil ideal del intelectual, conforme el término iba entrando en vigencia en las primeras décadas del siglo XX en América Latina, quedaría así resumido: "Un modelo de 'sujeto pensador' que se define en primer lugar por su género (masculino), luego por su madurez (relación con el trabajo, con el esfuerzo, con la utilidad), por último, con la ejemplaridad de su vida, que lo coloca en una cumbre" (Montaldo, 1999, p. 150). Pablo Neruda sería personificación de dicho modelo en la generación de Oliver: los cuestionamientos que hubiese podido despertar su actuación pública, entre pares y dispares ideológicos, no llegarían a desconocerle su lugar de intelectual. Poeta, militante comunista, autor del "Canto general" para América, delegado del Movimiento Internacional por la Paz, Premio Nobel de Literatura en 1971. Al igual que otras identidades subordinadas, las mujeres, en cambio, incluso cuando fueron reconocidas como "mujeres de letras" o escritoras destacadas, no estarían comprendidas en esta categoría sino hasta entrados los años setenta del

\footnotetext{
${ }^{27}$ Es normal la identificación con "El hombre de letras" - un intelectual tradicional en términos de Gramsci-. Según Nicola Miller (1999): "one key element in securing recognition as an intellectual in Spanish America specially during the first part of the twentieth century- was creativity. Those who has published a text of literary merit were granted a public platform that an average lawyer, medical practitioner or teacher was not. The potential of their social function as intellectuals was thereby greatly enhanced. This emphasis on creative writing was a result both of the historical power of the written word in Spanish America and of the legacy of late Romanticism with is emphasis on prophetic genius" (Miller, 1999, p. 26).
} 
siglo $\mathrm{XX}^{28}$, cuando las corrientes de pensamiento crítico y relativista dieran lugar al cuestionamiento del canon. El desarrollo del pensamiento feminista en las prácticas académicas, como dice Queiroz (1997): “tem levado à “substituição da eterna pergunta - $O$ que é literatura? por outra -¿O que é considerado literário, quando, em que circunstâncias, por quem e por quê?"” (p. 12).

Pero el poder de canonizar se mantiene en las instituciones académicas, logrando perpetuar la invisibilización de las mujeres en los campos literario e intelectual. El sesgo que denunciaba Pratt (1998) hace dos décadas al revisar antologías de ensayo y otros compendios literarios, donde solo figuraban algunas mujeres destacadas, sigue mostrando aún hoy pocas alteraciones al canon masculino (ver, por ejemplo, Jiménez y Morales, 1998; Paredes, 2008; Patiño y Calomarde, 2013; Verity, 1997). Todavía en el siglo XXI, el reconocimiento de la secular marginación de las mujeres en la concepción de lo intelectual, ha funcionado, contrario a lo que se esperaría, como un límite difícil de traspasar. En el importante trabajo de Historia de los intelectuales en América Latina, editado hace unos años por Carlos Altamirano (2008; 2010a) y Jorge Myers (2008), con artículos de varios de los investigadores e investigadoras más destacadas en el área, las mujeres son apenas acotadas en la presentación de los dos volúmenes bajo la premisa de su excepcionalidad en el campo cultural e intelectual del continente. La indicación de que en el siglo XX escritoras como "Rosario Castellanos, Victoria Ocampo, Cecilia Meireles, Clarice Lispector, Gabriela Mistral, y tantas otras" incidieron "qua intelectuales" en la vida cultural de sus respectivos países (Myers, 2008, pp. 42-43), no es suficiente para enriquecer un conjunto temático que igualmente les asigna un lugar menor. No se estudian allí sus producciones, sus trabajos como escritoras, pensadoras, editoras - con la salvedad de Victoria Ocampo y Sur-, como traductoras, o sus asociaciones y redes de afinidad.

Es importante señalar que el número de académicas que escriben en el volumen de Historia Intelectual corresponde casi a la mitad del total de autores. Presencia que supone una tensión con el espacio mínimo de reflexión sobre el trabajo intelectual de mujeres durante el siglo XIX: no porque en cuanto mujeres deban hablar sobre ello, sino porque la perspectiva incluyente de la publicación no se traduce en análisis críticos, casos, relatos en relación con el

\footnotetext{
${ }^{28}$ Según Nicola Miller (1999): "During the early twentieth century, the Chilean Gabriela Mistral, who won Latin America's first Nobel Prize for Literature in 1947, was regarded as una poetisa [a poetess] rather as an intellectual [...] Even in the 1990s, well after the introduction of Anglo-American and French feminist ideas into Spanish America during the 1960s and 1970s, women still found it difficult to win recognition as 'intellectuals', even when they have succeeded in stablishing themselves as writers, journalist or academics” (pp. 104-105).
} 
trabajo diverso de mujeres o de otros sujetos marginados e históricamente invisibilizados ${ }^{29}$. El primer tomo, por ejemplo, incluye un solo artículo relativo a la agencia feminista en el campo cultural de la Argentina de inicios del siglo XX, y ninguno sobre el trabajo de escritoras decimonónicas. En el segundo, se encuentran referencias a mujeres como Magda Portal, en relación con el movimiento aprista en el Perú (Bergel, 2010; Melgar, 2010; Terán, 2010) o a Victoria Ocampo, en el contexto de la historia y evolución de la revista Sur (Gramuglio, 2010), pero no aparece análisis alguno sobre la trayectoria o aportaciones de "tantas otras", célebres o no, cuyas intervenciones fueron significativas en las esferas del periodismo, la difusión cultural radial e impresa, la pedagogía, la crítica social, la administración pública, la negociación cultural y política, y el activismo social.

El vacío se hace insostenible en una compilación que, siendo hoy referente obligado de cualquier investigación dentro de los estudios culturales e intelectuales en América Latina, señala al tiempo la pluralidad de esa historia:

A medida que se ingrese en el siglo XX y a lo largo del resto de la centuria se puede registrar a hombres y mujeres, sean escritores o artistas, creadores o difusores, eruditos, expertos o ideólogos, en el papel que los hace socialmente más visibles: actores del debate público, el intelectual como ser cívico (Altamirano, 2010b, p. 9).

Siguiendo a Pura Fernández (2015) en su crítica al primer compendio:

Seguir fundamentando la idea de la excepcionalidad de la mujer de letras, cuya experiencia social y cultural desafía paradigmas institucionalizados en las historiografías literarias nacionales, supone desechar un corpus no canónico pero fundamental para el análisis de la historia cultural contemporánea (p. 17) ${ }^{30}$.

En este sentido, es indispensable asimismo evaluar las contribuciones de las intelectuales latinoamericanas a lo largo del siglo XX, e incluso repensar críticamente el papel

\footnotetext{
${ }^{29}$ El artículo de Dora Barrancos (2008), único entre los presentados, refuerza la constatación de este vacío en las primeras líneas: "No puede sorprender la invisibilidad que sufren las mujeres en esaišpis isaga [el magisterio de los letrados] toda vez que la historiografía ha demorado el reconocimiento de la participación femenina más allá de la vida doméstica. Pero resulta irrefutable que gran parte de la tarea pedagógica estuvo en aun antes de las transformaciones iniciadas con la presidencia de Domingo Faustino Sarmiento en la década de 1860" (pp. 465466).

${ }^{30}$ En cuanto al desconocimiento de autoras del siglo XIX como Juana Manso, Soledad Acosta de Samper o Clorinda Matto de Turner -por nombrar solo algunas-, lo anterior lleva a reproducir la invisibilización de "[...] escritoras que participaron activamente en la vida política, social, educativa y literaria de varias repúblicas, que lograron un amplio y variado corpus discursivo y que contribuyeron a la formación de los imaginarios que tejen los sistemas de representación cultural de las naciones" (Fernández, 2015, p. 17).
} 
de mujeres notables como Victoria Ocampo o Gabriela Mistral ${ }^{31}$. El cuestionamiento de la lógica canónica supone revisar el lugar del protagonismo que contribuye al ocultamiento de diversas trayectorias y a reproducir los valores de excepcionalidad. Tal y como afirma Buenahora Molina (2016):

Sin embargo, hay que cuidarse de los universalismos que terminan siendo parámetros de análisis para la literatura producida por mujeres, es decir, criticamos el canon pero tenemos la tendencia a construirnos uno nuevo en el que algunas autoras quedan al margen de la experiencia heroizante desde la cual erigimos estructuras de análisis que caen en la dinámica centro-periferia; así las escritoras regionales, con condiciones étnico raciales determinadas son ubicadas en "literaturas específicas" que no vienen a hacer parte de las "clásicas". La construcción de un nuevo canon no nos asegura que este será más incluyente (p. 198).

En el caso de María Rosa Oliver, esta última sería sin duda otra situación a considerar: el hecho de que su trabajo, en parte, haya quedado también eclipsado bajo el brillo de su homóloga Victoria Ocampo, además del de otros de sus ilustres colegas. Es sintomático en esta dirección la observación que hacía el escritor uruguayo Juan Carlos Onetti en una carta a María Rosa cuando fue publicada La vida cotidiana (Oliver, 1969) -el segundo libro de sus memorias. En esta, Onetti se preguntaba por qué ella no estaba "arrastrada por el deslumbrante boom que podría incluir, además, a Norah Lange y sus maravillosas 'Personas en la Sala" ${ }^{32}$. A propósito de un libro que sería editado en Sudamericana, donde figuraban, únicas mujeres, Victoria y Silvina Ocampo, Onetti reprochaba: "Parece que el mundo literario femenino en Santa María de los Buenos Aires empieza y termina con eso"33.

\footnotetext{
${ }^{31}$ En el caso de Mistral, por ejemplo, trabajos como los de Fiol-Matta (2002), Ana Pizarro (2005), o el estudio más reciente de Cabello Hutt (2018), disputan la tradicional imagen de la escritora chilena -poetisa, maestra abnegada y "madre" de América- para dar paso a análisis más complejos que atienden distintas facetas de su proyecto intelectual, sus estrategias de autofiguración e intervención pública y sus aportaciones a través de documentos antes desconocidos, como correspondencia, discursos, artículos periodísticos o de opinión, textos de crítica, entre otros. Esta América Nuestra, edición crítica de la correspondencia entre Mistral y Ocampo (2007), no solo muestran el desarrollo de la afectuosa, rica e intensa amistad intelectual entre estas dos mujeres, sino que permiten integrar otras perspectivas y registros a las reflexiones sobre el pensamiento americanista en la región, hasta ahora encapsulado sobre todo en los grandes intérpretes de la identidad latinoamericana -Martí, Rodó, Vasconcelos, Henríquez Ureña.

${ }^{32}$ Carta de Juan Carlos Onetti a María Rosa Oliver, 13 de diciembre, 1969. MROP, Series 2, Caja 5, Fólder 20.

${ }^{33}$ Carta de Juan Carlos Onetti a María Rosa Oliver, 13 de diciembre, 1969. MROP, Series 2, Caja 5, Fólder 20.
} 
Más allá de los sesgos particulares - pero no en vano la mención a la editorial fundada por Victoria Ocampo con otros intelectuales en 1939-, el comentario del escritor uruguayo es bastante expresivo. La directora de Sur, en especial, se convertiría muy rápidamente en un astro, en un caso ejemplar de la trayectoria pública de una mujer argentina. Para ese momento escritora reconocida -aunque también en fragmentos y con múltiples textos de índole biográfica-, Ocampo había compilado y publicado gran parte de sus escritos, y era, además, "mecenas", traductora y gestora. Muy temprano en su carrera, lograría un lugar destacado en el mundo literario argentino. "La primera mujer que toma una iniciativa cultural-institucional que afecta destinos intelectuales masculinos", nos recuerda Sarlo (2003, p. 24), e introducida al mundo literario con un prólogo de Ortega y Gasset a su libro De Francesca a Beatrice (1924). La arquitecta de Sur. Ocampo sí "llegó a ser escritora 'contra viento y marea, como le gustaba decir", insiste Molloy (1996, p. 88). Ya en 1979, cuando Ocampo tenía 88 años de edad, Doris Meyer publica Against the Wind and the Tide, estudio biográfico que presenta a la escritora argentina como la mujer que más logros alcanzó en el área cultural, en comparación con otras mujeres de su país -y tal vez de América Latina-, y cuyo nombre llegó a hacerse sinónimo tanto de la búsqueda de excelencia creativa, como de la consolidación de diálogos culturales entre naciones de todos los continentes (Meyer, 1990, p. xii).

La perspectiva y las memorias de Oliver serían con frecuencia tenidas por sugestivo contrapunto o por punto adicional de apoyo para dilucidar la especificidad de su amiga, en varios de los incontables estudios que, desde el clásico trabajo de Meyer (1990 [1979]), se han ocupado de aspectos de la vida y obra de Victoria Ocampo ${ }^{34}$. La vida cotidiana (1969), el libro más vendido de María Rosa Oliver en Buenos Aires $^{35}$, ha sido posteriormente considerado como una de las versiones pertinentes en la reconstrucción de la historia de Sures una de las fuentes del clásico estudio de King (1989), junto con entrevistas a la autora, e ineludible en los análisis de Gramuglio (1986; 2004; 2010; 2014) sobre la revista-. En este, María Rosa reconstruye el periodo de su adolescencia y juventud, desde los años previos a la

\footnotetext{
34 Entre los estudios biográficos más citadas de Ocampo, además del de Meyer, se cuentan: Omil (1980), Matamoro (1986), Vásquez $(1991 ;$ 2002). El nombre de Victoria Ocampo ha sido una constante en las evaluaciones sobre los aportes literarios o el trabajo de mujeres en Latinoamérica y el Cono Sur, o específicamente en el campo cultural porteño, desde finales de los setenta. Por mencionar solo algunos ejemplos, además de la ya "clásica" antología de Castro-Klaren, Sarlo y Molloy (1991), o los estudios de Castro-Klaren (2003) y Unruh (2006), cabe destacar algunos más recientes como los de Pierini (2014) o Rodríguez y Szurmuk (2016). Sin embargo, en ninguno de estos compendios o revisiones críticas, Oliver aparece referida o tematizada. ${ }^{35}$ En la presentación de La vida cotidiana que ofrece la revista Panorama, el libro se cuenta entre la lista de "Best Sellers", junto a títulos de narrativa como Close-up de Arthur Hailey (Emecé), Heroína de Emilio Rodríguez (Sudamericana), Sagrado de Tomás Eloy Martínez (Sudamericana) y La noche de los tiempos de René Barjavel (Emecé). Al final indican las librerías consultadas para la elaboración de esta lista: "Schapire, Dalmat, Rodríguez, Huemul, Paner, Ulises”. 24 de noviembre, 1969. MROP, Caja 9, Fólder 33.
} 
Primera Guerra Mundial hasta el estallido de la Guerra Civil Española, así como su integración a los círculos intelectuales de Buenos Aires. Allí narra sus encuentros y desencuentros con distintas personalidades de la época -como Alfonso Reyes, Pedro Henríquez Ureña, Waldo Frank, Federico García Lorca, Ricardo Güiraldes, Alfonsina Storni, Victoria y el grupo que gravitaría en torno a la revista; su amistad con Ocampo y sus proyectos conjuntos, incluido el proceso de creación de Sur y el origen de la Unión Argentina de Mujeres (UAM); sus actividades en las luchas contra el fascismo español y luego contra el nazismo. También algunos de sus primeros trabajos como traductora, editora, instructora, consejera, escritora. Según una breve reseña sobre el libro, publicada en la revista Panorama: "Las anécdotas de la vida literaria constituyen uno de los grandes atractivos de estas memorias" (S.a. 1969, p. 53).

Solo el tercer tomo de sus memorias, Mi fe es el hombre (1981) -el mismo que en su momento pasó "prácticamente desapercibido"-, ha sido una vez reeditado, en 2008, en una colección titulada "los raros". En contraste con la decena de estudios biográficos que se han producido sobre Victoria Ocampo, sobre Oliver contamos hoy con la biografía escrita por la historiadora argentina Hebe Clementi como parte de una colección de popularización histórica titulada "mujeres argentinas", publicada en $1992^{36}$.

\section{La mediadora}

La mayoría de los contados análisis que hasta el momento se han ocupado del trabajo de María Rosa, unos cuantos artículos o ponencias recientes, se basan en los tres tomos de sus memorias o en información proveniente de la biografía de Clementi. A Oliver se la emparenta en la línea de la autobiografía con mujeres como Victoria Ocampo, Nora Lange o Alicia Jurado en la Argentina (Catelli, 2004; 2007; Rigo de Alonso, 2010) -pero, de nuevo, son contados los textos y Ocampo suele ser quien "jalona” esos estudios-. Sylvia Molloy (1996) la refiere brevemente en su ya clásico estudio sobre la escritura autobiográfica en América Latina (en contraste con Ocampo y para identificarla en nota al pie a un escritor como Pablo Neruda con quien tiene en común la búsqueda de "coherencia ideológica" desde la infancia)

\footnotetext{
${ }^{36}$ La investigación se basa en una revisión tanto de las memorias de Oliver como de documentos del archivo personal, antes de ser donado a la Universidad de Princeton por la familia de Oliver en 1996. La narración se construye sobre la presentación de hechos destacados y con el objetivo fundamental de "dar a conocer". Buena parte del libro relata los tres tomos de la autobiografía de Oliver, completando el perfil y los años no narrados con entrevistas, el libro sobre China y documentos puntuales del archivo, como algunas de las escasas copias que guardó Oliver de las cartas enviadas por ella. Algunas de las más sugestivas indicaciones de Clementi, con todo y la clara confianza en que la trayectoria de Oliver es reflejo de una "coherencia total" con la vida y la libertad, quedan abiertas justamente a desarrollos posteriores. Referir a Oliver como una "grande del pensamiento en acción" (Clementi, 1992, p. 205), al final del libro, es una de ellas.
} 
(Molloy, 1996, p. 88 y p. 147). Por lo narrado en sus memorias y en la biografía señalada, en otros textos se la ha reconocido como una figura importante en las redes americanistas y comunistas (Fernández, 2009a; 2009b), o como figura estratégica para el Movimiento Internacional de Partidarios por la Paz (Petra, 2010; 2013a; 2013b). Algunos de los artículos sobre sus memorias se han ocupado de su autofiguración como viajera (Pierini, 2004) ${ }^{37}$ o lectora (Bertúa, 2012); o como mujer feminista, antifascista y comunista (Becerra, 2013a; 2015); o en relación con el problema del cuerpo, la maternidad y la ciudadanía (Becerra, 2013b; 2017), también de las representaciones de género y enfermedad en sus primeras memorias (Lojo, 2015); o en paralelo con Ocampo (Lojo, 2017). Pero, como se indicó arriba, a lo largo de su vida, María Rosa Oliver escribió también textos políticos, memorias de viajes, piezas periodísticas, crónicas, testimonios, cartas, discursos y ensayos.

En general, la amplia colección de documentos, textos y fotografías reunidos en el repositorio personal de María Rosa Oliver en la Universidad de Princeton -0 de piezas disponibles en otros archivos y colecciones- permanece ampliamente inexplorado. El estudio introductorio de la segunda edición de Mi fe es el hombre (Oliver, 2008), a cargo de Álvaro Fernández Bravo (2008), ofrece una contextualización crítica con referencias puntuales del epistolario de Oliver y enfatiza su posición como "doble agente" dentro de las redes culturales en expansión durante las décadas de 1930 y 1940. Pocos y muy recientes artículos, en relación con temas de renovado interés como la Guerra Fría Cultural y los intelectuales latinoamericanos (Iber, 2015), el latinoamericanismo, las redes comunistas y americanistas en la primera mitad del siglo XX (Fernández, 2017a), han examinado documentos específicos del archivo de la escritora -algunas cartas con Ocampo, Alfred Métraux (Fernández, 2017b), Gabriela Mistral (Pierini, 2017), una memoria sobre su participación en el Movimiento Internacional por la Paz (Petra, 2017), por ejemplo. Por su excepcionalidad en la consideración de registros y lecturas inéditas de la obra de Oliver, cabe destacar los análisis de Paula Bertúa (2013) que, teniendo en cuenta producciones más eclécticas, explora primero las contribuciones para un diario de viajes trasatlánticos y algunas otras publicaciones de la década de 1940, para enfocar el papel de Oliver como intermediaria cultural. Más recientemente, examina textos publicados por Oliver en medios de la prensa cultural

\footnotetext{
${ }^{37} \mathrm{La}$ imagen de Oliver viajera se cristaliza igualmente en algunas compilaciones sobre relatos de viaje de escritores y escritoras argentinas a Europa y Estados Unidos, donde se incluyen algunos apartados de los dos primeros volúmenes de su autobiografía (Jitrik, 1969; Losada, 2010). Ver también las referencias a la posición de Oliver respecto de su viaje a los Estados Unidos (De Navascués, 2014).
} 
antifascista de Buenos Aires, en el marco de un proyecto más amplio sobre intervenciones estéticas y políticas de mujeres en la cultura argentina, entre 1930 y 1950 (Bertúa, 2015).

Con una mirada panorámica, en conjunto, sobre la producción académica que ha tratado de alguna manera a Oliver, se puede observar que globalmente en esta ella destaca como mediadora o figura intermedia, y que esa posición se traduce en un lugar menor dentro de las tradiciones literarias e intelectuales latinoamericanas. Amiga/contacto de diversas e icónicas personalidades públicas; figura funcional o facilitadora en redes comunistas ancladas en Neruda, Amado, Asturias, también en redes americanistas leídas a través de Alfonso Reyes, Pedro Henríquez Ureña, Gabriela Mistral; o intelectual burguesa de táctica significación para el Partido Comunista. En general, no hay mayores exploraciones sobre lo producido por Oliver en estos frentes. Prevalecen zonas de su trabajo, o textos de su haber, indicados, pero no tratados. A veces publicaciones en general desatendidas por la crítica: artículos/testimonios publicados en Casa de las Américas -uno de los cuales es la memoria de su entrevista personal con el Che Guevara en la Habana, cuando viajó a la isla para ser jurado del Premio literario en 1964 (Oliver, 1968). Buena parte de los artículos de opinión, notas, reseñas, ensayos breves y testimonios de Oliver en Sur han sido escasamente atendidos. También parte de la correspondencia publicada de Alfonso Reyes (2009) donde se encuentra lo respectivo del epistolario de Oliver; o la intercambiada por María Rosa Oliver y el intelectual y sacerdote argentino Eugenio Guasta (Oliver y Guasta, 2011). Cabe exceptuar la inclusión de un fragmento del libro escrito en co-autoría sobre la República Popular China en el estudio de Sylvia Saítta (2007) sobre Viajeros Argentinos de Izquierda, sobre el que, sin embargo, no hay lecturas posteriores.

No llega a sorprender por ello que en un artículo reciente publicado en monográfico con algunos de los arriba $\operatorname{citados}^{38}$, se hallen ecos de los juicios de Borges y de sus contemporáneos. Según el autor:

El desmoronamiento de la URSS en 1991 produjo un cambio en el equilibrio internacional que María Rosa Oliver, desde su mentalidad utópica, no podría haber vislumbrado ni aceptado. La sensación que deja su accionar es, por ello, sumamente paradójica y quizás patética

\footnotetext{
${ }^{38}$ Las contribuciones de un coloquio que reunía a varios de los investigadores e investigadoras que muy recientemente han comenzado a enfocar distintos aspectos del trabajo de Oliver, con el propósito de visibilizar a una distinguida escritora de su tiempo que ha sido poco atendida por los estudios literarios, fueron publicadas en el último número de 2017 de la revista Mora, en un monográfico dedicado a pensar varios de "los recorridos vitales e intelectuales de la escritora María Rosa Oliver (1898-1977)" (Bertúa 2017, p. 4). Estas representan sin duda uno de los primeros intentos por agrupar lecturas actuales en torno a su figura.
} 
si se considera su figura de mujer de la periferia y minusválida luchando contra las fuerzas de Goliat [énfasis agregado] (Amícola, 2017, p. 19).

\section{Conclusiones}

We need to know the writing of the past, and know it differently than we have ever know it; not to pass on a tradition but to break its hold over us (Rich, 1972, p. 19).

María Rosa Oliver fue una de las mujeres que en el siglo XX intervino qua intelectual en los escenarios político culturales no solo de la Argentina, sino también del continente americano. Fue "una de las mujeres del grupo Sur"39, núcleo intelectual protagónico del mundo cultural latinoamericano de la primera mitad del siglo XX. Y lo primero que llama la atención es que, a diferencia de sus colegas Victoria y Silvina Ocampo, o Nora Lange, su trabajo ha generado poquísimo interés. Al igual que estas, y otros de sus amigos escritores, Oliver desempeñó diversos oficios intelectuales en el campo cultural de su tiempo. Como María Rosa, el poeta Pablo Neruda fue primero afín a la política del gobierno Roosevelt y luego -él como militante del Partido Comunista, Oliver como "compañera de ruta"-, fue miembro activo del Movimiento Internacional de Partidarios por la Paz. Este último galardonado con el Premio Stalin de la Paz en 1953, antes de que fuera renombrado como "Premio Lenin" en 1956 -con el proceso de desestalinización de la Unión Soviética. Como Oliver, Victoria Ocampo cuenta con una extensa selección de escritos breves, testimonios, ensayos cortos, crónicas de viaje, producciones fragmentarias, pero una buena porción de estos fue editada por ella en vida.

Hay una pauta primaria en las prácticas de lectura que afectan la valoración histórica, literaria e intelectual de una figura como María Rosa Oliver: la aparente ausencia de obra. Primero como una carencia, una falta de bibliografía y de obra editada; luego como una ausencia sujeta a la centralidad de sus tomos de memorias en las escasas ponderaciones sobre

\footnotetext{
${ }^{39}$ Así me la presentó el profesor argentino Román Setton cuando hacía una estancia académica en Berlín, al inicio de mi doctorado. Había encontrado un dato, si recuerdo bien, en sus investigaciones sobre el director Luis Saslavsky, de quien María Rosa Oliver era amiga cercana. Una fugaz referencia al final del capítulo dedicado a él en el libro "Argentinos de raza" había llamado su atención por la posibilidad de identificar fuentes sobre este director tan poco conocido y estudiado en la Argentina: "Pocos saben que en un museo de Washington se atesoran escritos de María Rosa Oliver - gracias al interés y al respeto que suelen tener los norteamericanos por intelectuales de otras latitudes- entre los cuales hay ochenta cartas que le escribió Victoria Ocampo, cuarenta de Waldo Frank y ciento veintiséis de Luis Saslavsky" (Lagos, 2003, p. 77). El archivo de María Rosa no se encuentra en Washington (pueda ser que allí haya estado primero), sino que, como se indicó, se conserva en la biblioteca central de la Universidad de Princeton.
} 
su producción escrita. Las lecturas están generando así un vacío: el vacío de la "obra”. Si en casos como los de Gabriela Mistral, Victoria Ocampo, Alfonso Reyes o Pedro Henríquez Ureña, las correspondencias editadas entran a sumar a un estatus ya ganado de escritores, en el de Oliver estas prácticamente no han sido tratadas en conexión con su propio lugar como escritora. Entre los procesos de lectura se perfila además una tensión respecto del papel de "la mujer intelectual": entre aquella burguesa en "sillita" de ruedas que, sin "obra" previa a sus memorias, difícilmente puede ser entonces catalogada junto con otras/otros escritores, y aquella que en la crítica actual va abriéndose camino como una de las mujeres escritoras a recuperar del olvido -aunque prevalecen ciertos mecanismos que reproducen la invisibilización-.

El contraste entre Ocampo y Oliver, por ejemplo, sirve no para dejarlas configuradas dentro de ese universo de escrituras femeninas, en el que una de ellas tiene mayor visibilidad y es hoy tratada en sus diferentes facetas - por lo que hacer justicia a la otra significaría rescatarla en esa misma medida-, sino para cuestionar la propia práctica (canónica) de lectura que genera estas proporciones. No se trata de restituir una centralidad merecida, sino de procurar otros puntos de vista. ¿Cómo desmontar el canon si no cambiamos esas prácticas, además de las categorías de género(s) instituidas para comprender una obra intelectual o literaria? Siendo una constante el vacío de lectura en torno a la escritura de Oliver, poner bajo sospecha la exclusiva atención en sus memorias autobiográficas supone, de entrada, cuestionar su encasillamiento en esta única voz narrativa, válida por su forma(to) como obra sobre los otros "géneros menores", y reconocer la necesidad e importancia de otros registros de lucha, creación y constitución intelectual.

Ahora bien, la autobiografía de mujeres es sin duda un género fundamental en la operación de subvertir desde el lugar asignado, y las lecturas críticas que ha atraído la obra autobiográfica de María Rosa Oliver han problematizado, desde diferentes ángulos, representaciones sobre ciudadanía, cuerpo, género, clase, memoria y enfermedad. Su narrativa ha sido también revisada con perspectiva feminista. Por ello, el cuestionamiento se dirige, no contra las posibilidades críticas que abre el análisis de sus memorias, sino contra el hecho de que estas memorias prevalezcan como mecanismo de validación de la obra. Respondo al problema del canon que exige estudiar sus libros y desconoce así diversos géneros de expresión textual, entre lo literario y lo no literario, entre el testimonio personal y el análisis político e histórico, que trascienden límites formales y configuran otros modos de subversión de las fronteras establecidas entre lo público y lo privado. Considerar seriamente la obra 
dispersa y desatendida abre el camino a nuevas miradas sobre la propia obra autobiográfica, pero sobre todo permite desafiar la idea del registro aún más personal que se le atribuye a esta escritura, el paralelismo que dicha atribución tiene con el lugar doméstico e íntimo secularmente asignado a la mujer y la consiguiente negación, en este caso, del vínculo entre pensamiento-escritura-acción en la vida pública de Oliver que, como vimos, también se intersecta con des/calificaciones de discapacidad y posición mediadora.

El gesto canónico, nos ha recordado Ludmer, consiste en ubicar a la/al otra/otro desde la carencia y se mantiene en el acto ficticio de dar la palabra, de conceder y al tiempo fijar la presunta especificidad de ese lenguaje. Dar a Oliver la voz del altruismo, el sacrificio y la bondad, el relato de superación, como una manifestación natural de su situación de discapacidad termina por reducir el lugar ya de por sí devaluado de la mediación -en contraposición a la normativa de obra-, presente en textos como cartas, discursos, conferencias o "notas esclarecedoras del momento"; también en oficios como el de editora, traductora, asesora cultural, consejera, reportera o "testigo". Debe operarse un desplazamiento del lugar asignado a esa posición, hacia el de la cualidad política y creativa de la mediación a través de la obra dispersa, que ilumina en cambio la agencia implicada en la decisión de no publicar o la agencia de esa misma visibilidad del cuerpo en silla de ruedas. De lo contrario, la posición de mediadora funciona también como instrumento de in/visibilización, o mejor, de visibilización elusiva: una ausencia en el hecho de presentar y un desconocimiento en el hecho de reconocer, cuando al nombrar se está eludiendo el enfrentamiento con $s u$ obra. En pocas palabras, se trata de enfrentar las lógicas de desplazamiento intelectual de una escritora para romper el poder de la ficción heterodesignada que ha hecho de Oliver una "visible ausente" en la historia cultural y literaria latinoamericana: un personaje y no una presencia, una caricatura de la paz, una "animadora cultural” o una ingenua utópica.

Es necesario re-evaluar la figura del escritor configurada por y desde un canon autorreferencial incapaz de dar cuenta de otras prácticas de escritura y de otros posibles vínculos entre escritura y praxis política. El valor de esos textos sueltos, dispersos, o en archivos, es que nos dan otras luces sobre las tradiciones literarias de las mujeres, nos permiten conocer los modos en que estas se han enfrentado a sus condiciones actuales, sus adaptaciones, luchas y resistencias a través de la escritura. 


\section{Referencias bibliográficas}

Altamirano, Carlos. (2008). Introducción general. En Carlos Altamirano (Dir.) y Jorge Myers (Ed.), Historia de los intelectuales en América Latina I. (pp. 9-27). Madrid, España: Katz Editores.

Altamirano, Carlos. (Dir./Ed.). (2010a). Historia de los intelectuales en América Latina II. Los avatares de la "ciudad letrada” en el siglo XX. Madrid, España: Katz Editores.

Altamirano, Carlos. (2010b). Introducción al volumen II. Élites culturales en el siglo XX latinoamericano. En Carlos Altamirano (Dir./Ed.), Historia de los intelectuales en América Latina II (pp. 10-29). Madrid, España: Katz Editores.

Altamirano, Carlos. (2013). Intelectuales. Notas de investigación sobre una tribu inquieta. Buenos Aires, Argentina: Siglo XXI Editores.

Alzate, Carolina, y Doll, Darcie (Comps.). (2014). Redes, alianzas y afinidades. Mujeres y escritura en América Latina. Homenaje a Monserrat Ordoñez (1941-2011). Bogotá, Colombia/Santiago de Chile, Chile: Universidad de los Andes/Universidad de Chile.

Amícola, José. (2017). María Rosa Oliver y la utopía. Mora, 23(2), 19-26.

Baert, Patrick. (2015). The Existentialist Moment. The Rise of Sartre as a Public Intellectual. Malden, Reino Unido: Polity Press.

Balderston, Daniel. (2004). Encyclopedia of Twentieth-Century Latin American and Caribbean Literature. Londres, Reino Unido: Routledge.

Barrancos, Dora. (2008). Maestras, librepensadoras y feministas en la Argentina. En Carlos Altamirano (Dir.) y Jorge Myers (Ed.), Historia de los Intelectuales en América Latina I (pp. 465-491). Buenos Aires: Argentina Katz Editores.

Becerra, Marina. (2013a). Género y antifascismo en la autobiografía de María Rosa Oliver. Estudios Avanzados, (20), 97-114.

Becerra, Marina. (2013b). Maternidad y ciudadanía en la Argentina de principios del siglo XX: un análisis de la autobiografía de María Rosa Oliver. A Contracorriente, 10(2), 202-218.

Becerra, Marina. (2015). María Rosa Oliver (1898-1977), de la historia a la autobiografía. Arenal, 22(1), 31-47. 
Becerra, Marina. (2017). ¿Un cuerpo propio? Formas de la representación femenina, resistencia y reproducción en la Argentina de inicios del siglo XX: un análisis a través de la autobiografía de María Rosa Oliver (1898-1977). Cuadernos Pagu 50 (versión en línea). Recuperado de https://www.pagu.unicamp.br/pt-br/cadernos-pagu

Bergel, Martín. (2010). La desmesura revolucionaria. Prácticas intelectuales y cultura vitalista en los orígenes del APRA peruano (1921-1930). En Carlos Altamirano (Dir./Ed.), Historia de los intelectuales en América Latina II (pp. 301-324). Madrid, España: Katz Editores.

Bergmann, Emilie, Greenberg, Janet, Kirkpatrick, Gwen, Masiello, Francine, Miller, Francesca, Morello-Frosch Marta, y Newman, Kathleen. (1992). Women, Culture, and Politics in Latin America. Seminar on Feminism \& Culture in Latin America (19901991). Berkeley, Estados Unidos: University of California Press.

Bertúa, Paula. (2012). María Rosa Oliver: de la biblioteca heredada a la biblioteca conquistada. María Guadalupe Silva (Coord.), Literatura latinoamericana y representación. Diez ensayos críticos (pp. 69-80). Buenos Aires: NJ Editor.

Bertúa, Paula. (2013). María Rosa Oliver: apuntes de viaje y crítica cultural. Boletín del Centro de Estudios de Teoría y Crítica Literaria (17), 1-34.

Bertúa, Paula. (2015). "Si me quieres escribir...". Mujeres en la prensa cultural antifascista argentina (1930-1940). ARENAL, 22(1), 5-30.

Bertúa, Paula. (2017). Presentación del dossier "María Rosa Oliver: Trayectos de una escritora descentrada". Mora 23(2), 1-4.

Bioy, Adolfo. (2006). Borges. Barcelona, España: Ediciones Destino.

Blazquez, Norma, y Castañeda, Marta (Coords.). (2016). Lecturas críticas en investigación feminista. Ciudad de México, México: UNAM.

Bourdieu, Pierre. (2002). Campo de poder, campo intelectual. Itinerario de un concepto. Buenos Aires, Argentina: Editorial Montressor.

Buenahora, Giobanna. (2016). Escribir para no ser silenciadas: mujeres, literatura y epistemología feminista. En Norma Blazquez y Martha P. Castañeda (Coords.), Lecturas críticas en investigación feminista (pp. 195-216). Ciudad de México, México: UNAM 
Cabello, Claudia. (2018). Artesana de sí misma: Gabriela Mistral, una intelectual en cuerpo y palabra. West Lafayette, Estados Unidos: Purdue University.

Castro-Klaren, Sara. (2003). Narrativa femenina en América Latina. Prácticas y perspectivas teóricas, Madrid: Iberoamericana.

Castro-Klaren, Sara, Sarlo, Beatriz, y Molloy, Sylvia. (1991). Women's Writing in Latin America: An Anthology, San Francisco: Westview Press.

Catelli, Nora. (2004). La veta autobiográfica. En Noé Jitrik (Dir.) y Sylvia Saítta (Ed.), Historia crítica de la literatura argentina. Vol. 9: El oficio se afirma (pp. 145-169). Buenos Aires, Argentina: Emecé.

Catelli, Nora. (2007). En la era de la intimidad. Rosario, Argentina: Beatriz Viterbo Editora.

Clementi, Hebe. (1992). María Rosa Oliver. Buenos Aires, Argentina: Ed. Planeta.

De Navascués, Javier. (2014). Viajes de regreso en escritores de la revista Sur: Mallea, Bioy Casares y María Rosa Oliver. En Andreas Gelz y Marco Thomas Bosshard (Eds.), Return Migration in Romance Cultures (pp. 219-237). Friburgo/Berlín, Alemania: Rombach.

Dosse, Francois. (2007). La marcha de las ideas. Historia de los intelectuales, historia intelectual. Valencia, España: Universitat de València.

Ecker, Gisela (Ed.). (1986). Estética Feminista. Londres, Reino Unido: Women's Press Limited.

Fernández, Pura (Ed.). (2015). No hay nación para este sexo. La Re(d)pública transatlántica de las escritoras españolas y latinoamericanas (1824-1936). Madrid/Frankfurt, España/Alemania: Iberoamericana/Vervuert.

Fernández, Álvaro. (2008). Introducción a Mi fe es el hombre. En María Rosa Oliver, Mi fe es el hombre [2da Edición] (pp. 9-49). Buenos Aires, Argentina: Ediciones Biblioteca Nacional.

Fernández, Álvaro. (Mayo de 2009a). Redes culturales: El latinoamericanismo y sus bordes. En Estados de la cuestión: Actualidad de los estudios de teoría, crítica e historia literaria. Simposio llevado a cabo en el VII Congreso Internacional Orbis Tertius de Teoría y Crítica Literaria, La Plata, Argentina. 
Fernández, Álvaro. (2009b). Redes latinoamericanas en los años cuarenta: la revista Sur y el mundo tropical. En Claudio Maíz y Álvaro Fernández Bravo (Eds.), Episodios en la formación de redes culturales en América Latina (pp. 113-135). Buenos Aires, Argentina: Prometeo Libros.

Fernández, Álvaro. (2017a). El museo vacío: acumulación primitiva, patrimonio cultural e identidades colectivas Argentina y Brasil, 1880-1945. Buenos Aires, Argentina: Eudeba.

Fernández, Álvaro. (2017b). María Rosa Oliver en las redes comunistas del siglo. Mora, 23(2), 27-41.

Fiol-Matta, Licia. (2002). A Queer Mother for the Nation: The State and Gabriela Mistral. Minneapolis, Estados Unidos: University of Minnesota.

Frank, Gelya. (2000). Venus on Wheels: Two Decades of Dialogue on Disability, Biography, and Being Female in America. Berkeley: University of California Press.

Gramuglio, María. (1986). Sur: constitución del grupo y proyecto cultural. Punto de Vista IV, (17), 7-9.

Gramuglio, María. (2004). Posiciones de Sur en el espacio literario. Una política de la cultura. En Noé Jitrik (Dir.) y Sylvia Saítta (Ed.), Historia crítica de la literatura argentina. Vol. 9: El oficio se afirma (pp. 93-122). Buenos Aires, Argentina: Emecé.

Gramuglio, María. (2010). Sur. Una minoría cosmopolita en la periferia occidental. En Carlos Altamirano (Dir./Ed.), Historia de los intelectuales en América Latina II (pp. 193210). Madrid: Katz Editores.

Gramuglio, María. (2014). Sur en los años cuarenta. Políticas de la literatura. En Vicente Cervera Salinas y Ma. Dolores Adsuar (Eds.), Sur. Vínculos ensayísticos e interculturales en Sur (pp. 13-26). Murcia, España: Universidad de Murcia.

Iber, Patrick. (2013). El imperialismo de la libertad: El congreso por la Libertad de la Cultura (1953-1971). En Benedetta Calandra y Marina Franco (Eds.), La guerra fría Cultural en América Latina. Desafíos y límites para una nueva mirada a las relaciones interamericanas (pp. 117-132). Buenos Aires, Argentina: Editorial Biblos.

Iber, Patrick. (2015). Neither Peace, nor Freedom. The Cultural Cold War in Latin America. Cambridge, Estados Unidos: Harvard University Press. 
Jiménez, José, y Morales, Carlos. (1998). La prosa modernista hispanoamericana. Introducción crítica y antología. Madrid, España: Alianza Editorial.

Jitrik, Noé. (1969). Los viajeros. Buenos Aires, Argentina: Jorge Álvarez.

King, John. (1989). Sur. Estudio de la revista literaria argentina y de su papel en el desarrollo de una cultura 1931-1970. México D.F.: Fondo de Cultura Económica.

Lagos, Ovidio. (2003). Argentinos de raza. Buenos Aires: Emecé Editores.

Lojo, María. (2015). Memoria, género y enfermedad en Mundo, mi casa, de María Rosa Oliver. Confluencia, 30(2), 17-25.

Lojo, María. (2017). María Rosa Oliver (1898-1977) y Victoria Ocampo (1890- 1979): Dos maneras de narrar el Yo. Mora, 23(2), 42-53.

Losada, Leandro (Ed.). (2010). Esplendores del Centenario. Relatos de la elite argentina desde Europa y Estados Unidos. Buenos Aires, Argentina: Fondo de Cultura Económica.

Ludmer, Josefina. (1985). Las tretas del débil. En Patricia Elena González y Eliana Gómez (eds.), La sartén por el mango (pp. 47-54). Río Piedras: Ediciones Huracán.

Martínez, Tomás. (1969). Sobre erizos y hombres. Sur, (321), 69-71.

Masiello, Francine. (1997). Entre civilización y barbarie. Mujeres, nación y cultura literaria en la Argentina moderna. Rosario, Argentina: Beatriz Viterbo Editora.

Matamoro, Blas. (1986). Genio y figura de Victoria Ocampo. Buenos Aires, Argentina: Editorial Universitaria de Buenos Aires.

Melgar, Ricardo. (2010). Huellas, redes y prácticas del exilio intelectual aprista en Chile. En Carlos Altamirano (Dir./Ed.), Historia de los intelectuales en América Latina II (pp. 146-166). Madrid, España: Katz Editores.

Meyer, Doris. (1990) [1979]. Victoria Ocampo. Against the Wind and the Tide. Texas, Estados Unidos: University of Texas Press.

Miller, Nicola. (1999). In the Shadow of the State. Intellectuals and the Quest for National Identity in Twentieth-Century Spanish America. Londres/Nueva York, Reino Unidos/Estados Unidos: Verso. 
Mistral, Gabriela., y Ocampo, Victoria. (2007). Esta América nuestra. Correspondencia 1926-1956 (edición y estudio introductorio de Elizebth Horan y Doris Meyer). Buenos Aires, Argentina: El Cuenco de Plata.

Molloy, Sylvia. (1996). Acto de presencia. La escritura autobiográfica en Hispanoamérica. México D.F., México: El Colegio de México.

Montaldo, Graciela. (1999). Ficciones culturales y fábulas de identidad en América Latina. Rosario, Argentina: Beatriz Viterbo Editora.

Myers, Jorge. (2008). Introducción al volumen I. Los intelectuales latinoamericanos desde la colonia hasta inicios del siglo XX. Carlos Altamirano (Dir.) y Jorge Myers (Ed.), Historia de los intelectuales en América Latina (pp. 29-50). Madrid, España: Katz Editores.

Ocampo, Victoria. (1965). Recuerdos sobre recuerdos (al margen de Mundo, mi casa). Sur, (295): 79-85.

Oliver, María. (1939). Geografía infantil de la Argentina. Buenos Aires, Argentina: Editorial Sudamericana.

Oliver, María. (1945). América vista por una mujer argentina. Buenos Aires, Argentina. Salzmann y Cía.

Oliver, María. (1965). Mundo, mi casa. Buenos Aires, Argentina: Falbo Editores.

Oliver, María. (1968). Solamente un testimonio. Casa de las Américas, VIII(47), 91-94.

Oliver, María. (1969). La vida cotidiana. Buenos Aires, Argentina: Sudamericana.

Oliver, María. (1981). Mi fe es el hombre. Buenos Aires, Argentina: Ediciones Carlos Lohlé.

Oliver, María. (2008). Mi fe es el hombre. [2da edición]. Buenos Aires, Argentina: Ediciones Biblioteca Nacional [Colección Los Raros].

Oliver, María., y Frontini, Norberto. (1955). Lo que sabemos hablamos...Testimonio de la China de hoy. Buenos Aires, Argentina: Edición Botella al Mar.

Oliver, María Rosa., y Guasta, Eugenio. (2011). Correspondencia 1960-1976 [Edición al cuidado de Ernesto Montequin]. Buenos Aires, Argentina: Editorial Sur.

Omil, Alba. (1980). Frente y perfil de Victoria Ocampo. Buenos Aires, Argentina: SUR. 
Orgambide, Pedro. (1988). El escritor entre todos. Entre todos, año II (18): 44. Tomado de http://www.ruinasdigitales.com/revistas/Entre\%20Todos\%2018.pdf (16 de junio de 2014).

Orgambide, Pedro., y Yahni, Roberto. (1970). Enciclopedia de la literatura argentina. Buenos Aires: Editorial Sudamericana.

Palermo, Alicia. (2006). El acceso de las mujeres a la eduación universitaria. Revista argentina de Sociología, (4), 11-46.

Paredes, Alberto. (2008). El estilo es la idea: ensayo literario hispanomericano del siglo XX (antología crítica). México D.F., México: Siglo XXI Editores.

Patiño, Roxana, y Calomarde, Nancy. (2013). Escrituras latinoamericanas: literatura, teoría y crítica en debate. Córdoba, Argentina: Alción Editora.

Petra, Adriana. (2010). Cosmopolitismo y nación. Los intelectuales comunistas argentinos en tiempos de la Guerra Fría (1947-1956). Historia y problemas del siglo XX, 1(1), 5173.

Petra, Adriana. (2013a). Cultura comunista y Guerra Fría: los intelectuales y el Movimiento por la Paz en la Argentina. Cuadernos de Historia, (38), 99-130

Petra, Adriana. (2013b). Intelectuales comunistas en la Argentina (1945-1963) (disertación doctoral). Universidad Nacional de la Plata, La Plata, Argentina.

Petra, Adriana. (2017). "Rosita la roja". María Rosa Oliver y el mundo comunista de posguerra. Mora, 23(2), 54-68.

Pierini, Margarita. (2004). El viaje como iniciación en las memorias de María Rosa Oliver. En Luz Elena Zamudio (Ed.), Espacio, viajes y viajeros en la literatura latinoamericana, (pp. 122-138). México D.F., México: Ed. Aldous/UAM-I.

Pierini, Margarita. (Ed.). (2014). Escritoras latinoamericanas del siglo XX. Madrid: España MAIA Ediciones.

Pierini, Margarita. (2017). María Rosa Oliver: mundo (de letras), su casa. Mora, 23(2), 5-18.

Pizarro, Ana. (2005). Gabriela Mistral. El proyecto de Lucila. Santiago de Chile, Chile: LOM Ediciones.

Pratt, Marie. (1998). "Don’t interrupt me". The Gender Essay as Conversation and Countercanon. Revista Brasileira de Literatura Comparada, (4), 85-101. 
Queiroz, Vera. (1997). Crítica literária e estrategia de gênero. Niterói, Brasil: Editora da Universidade Federal Fluminense.

Rama, Ángel. (1965). Las memorias de María Rosa Oliver: La fascinación del mundo. Marcha XXVII, 29.

Rama, Ángel. (1985). Las máscaras democráticas del modernismo. Montevideo, Uruguay: Fundación Ángel Rama.

Rama, Ángel. (1998) [1984]. La ciudad letrada. Montevideo, Uruguay: Arca.

Reyes, Alfonso. (2009). Más epistolarios rioplatenses de Alfonso Reyes (edición y estudio introductorio de Serge Zaïtzeff), México D.F.: Universidad Autónoma Metropolitana.

Rich, Adrienne. (1972). "When We Dead Awaken": Writing as Re-vision. College English, 34(1), 18-30.

Rigo de Alonso, Viviana. (2010). Mujeres y escritura de vida: la autobiografía femenina en la Argentina del siglo XX. María Rosa Oliver, Victoria Ocampo y Alicia Jurado (disertación doctoral). Montreal, Canadá: McGill University.

Rodríguez, Ileana, y Mónica Szurmuk. (Eds.). (2016). The Cambridge History of Latin American Women's Literature, New York: Cambridge University Press.

Russ, Joanna. (2018). Cómo acabar con la escritura de las mujeres. Sevilla/Madrid, España: Editorial Barrett/Editorial Dos Bigotes.

S.a. 1965. Memoria de una pasión argentina. En Panorama, año VII, no. 134, 18 al 24 de noviembre de 1969, p. 53.

Saítta, Sylvia. (Ed.). (2007). Hacia la revolución: viajeros argentinos de izquierda. Buenos Aires, Argentina: Fondo de Cultura Económica.

Salomone, Alicia, Luongo, Gilda, Cisterna, Natalia, Doll, Darcie, y Queirolo, Graciela. (2004). Modernidad en otro tono. Escritura de mujeres latinoamericanas: 1920-1950. Santiago de Chile, Chile: Editorial Cuarto Propio.

Salomone, Alicia, Amaro, Lorena, y Pérez, Ángela. (Eds.). (2010). Caminos y desvíos. Lecturas críticas sobre género y escritura en América Latina. Santiago de Chile, Chile: Editorial Cuarto Propio.

Sebreli, Juan. (2005). El tiempo de una vida. Buenos Aires, Argentina: Editorial Sudamericana. 
Sebreli, Juan. (2011). Cuadernos. Buenos Aires, Argentina: Editorial Sudamericana.

Sarlo, Beatriz. (2003). Una modernidad periférica. Buenos Aires 1920-1930. Buenos Aires, Argentina: Nueva Visión.

Scott, Joan. (1992). El problema de la invisibilización. En Carmen Ramos Escandón (Comp.), Género e historia: la historiografía de la mujer, (pp. 38-65). Editorial Instituto Mora.

Scott, Joan. (2001). Experiencia. La ventana 13, $42-73$.

Smith, Verity. (1997). Encyclopedia of Latin American Literature. Londres/Chicago, Reino Unido/Estados Unidos: Fitzroy Dearborn.

Sontag, Susan. (1991). Illness as Metaphor \& Aids and its Metaphors. Londres /Nueva York: Penguin Books.

Sosa de Newton, Lily. (1967). Las argentinas de ayer y hoy. Buenos Aires, Argentina: Ediciones Zanetti.

Terán, Óscar. (2010). Amauta: vanguardia y revolución. En Carlos Altamirano (Dir.), Historia de los intelectuales en América Latina II, (pp. 169-191). Madrid, España: Katz Editores.

Unruh, Vicky. (2006). Intervening Acts. Performing Women and Modern Literary Culture in Latin America. Austin, Estados Unidos: University of Texas Press.

Vásquez, María. (1991). Victoria Ocampo. Buenos Aires, Argentina: Planeta.

Vásquez, María. (2002). Victoria Ocampo: el mundo como destino. Buenos Aires, Argentina: Seix Barral.

Viñas, David. (2008). Viajeros argentinos a Estados Unidos. Buenos Aires, Argentina: Santiago Arcos Editor.

Weigel, Sigrid. (1986). La mirada bizca: sobre la historia de la escritura de las mujeres. En Gisela Ecker (Ed.), Estética Feminista, (pp. 69-98). Londres, Reino Unido: Women's Press Limited. 


\section{Archivos referenciados}

Waldo Frank Papers. Centro de Colecciones Especiales Kislak, División de Libros raros y manuscritos, Universidad de Pennsylvania.

María Rosa Oliver Papers. División de Manuscritos, Departamento de Libros raros y Colecciones especiales, Biblioteca central de la Universidad de Princeton. 